\title{
Recurrent Cardiac Constriction after Implantation of an Expanded Polytetrafluoroethylene Surgical Membrane
}

\author{
Paul-Cătălin Puiu ${ }^{1,2}$ Matthias Siepe ${ }^{1,2}$ Wolfgang Zeh ${ }^{2,3}$ Emmanuel Zimmer ${ }^{1,2}$ \\ ${ }^{1}$ Department of Cardiovascular Surgery, Universitäts-Herzzentrum \\ Freiburg Bad Krozingen, Bad Krozingen, Baden Württemberg, \\ Germany \\ 2 Faculty of Medicine, Albert-Ludwigs-University of Freiburg, Freiburg, \\ Address for correspondence Paul-Cătălin Puiu, MDs, Department of \\ Cardiovascular Surgery, Universitäts-Herzzentrum Freiburg Bad \\ Krozingen, Südring 15, Bad Krozingen, Baden Württemberg 79189, \\ Germany (e-mail: puiupaulcatalin@gmail.com).
} Germany

${ }^{3}$ Department of Cardiology, Universitäts-Herzzentrum Freiburg Bad Krozingen, Bad Krozingen, Baden-Württemberg, Germany

Thorac Cardiovasc Surg Rep 2022;11:e1-e3.

\begin{abstract}
Keywords

- pericardium

- cardiac surgery

- surgery

One of the challenges compounding the complexity of reoperative cardiac surgery is the surgical adhesion, which can be responsible for adverse intraoperative events. Implantation of a substitute neo-pericardium has become a frequently used solution, with currently rising numbers of reoperations. We report the case of a 38-year-old man who developed recurrent delayed cardiac constriction following the implantation of an expanded polytetrafluoroethylene neo-pericardium. Careful preoperative planning is recommended to plan the optimal method of pericardioplasty, taking into account the pros and cons of each available material.
\end{abstract}

\section{Introduction}

One of the challenges compounding the complexity of reoperative cardiac surgery are the surgical adhesions, which can be responsible for adverse intraoperative events. ${ }^{1} \mathrm{Clo}-$ sure of the native pericardium is not always possible and in such situations implantation of a substitute neo-pericardium has become a frequently used solution for avoiding injuries to the heart and great vessels, with currently rising numbers of reoperations. ${ }^{1,2}$

The safety and efficacy of the Gore-Tex surgical membrane (SM) have been already reported. Scanning electron microscopic examination demonstrated neither cellular ingrowth nor immunocompetent cellular elements.,4 The patients reoperated had no adhesions and the dissection was reported to be easier.
In this report we present a case of recurrent delayed cardiac constriction after implantation of GORE PRECLUDE Pericardial Membrane SM.

\section{Clinical Summary}

A 38-year-old man $(187 \mathrm{~cm}, 115 \mathrm{~kg}$, body mass index 32.9 $\mathrm{kg} / \mathrm{m}^{2}$ ) with a history of hypertension, hypercholesterolemia, smoking, and constrictive pericarditis was admitted with progressive dyspnea, fatigue, and peripheral congestion. Echocardiography showed a moderate aortic insufficiency and a bicuspid Sievers type 1 aortic valve. Computed tomographic angiography revealed an ascending aortic aneurysm with a diameter of $48 \mathrm{~mm}$ and a thickened pericardium. Coronary angiography results were normal. received

March 31, 2021

accepted after revision

July 1,2021
DOI https://doi.org/

$10.1055 / \mathrm{s}-0041-1736456$.

ISSN 2194-7635. (c) 2022. The Author(s).

This is an open access article published by Thieme under the terms of the Creative Commons Attribution-NonDerivative-NonCommercial-License, permitting copying and reproduction so long as the original work is given appropriate credit. Contents may not be used for commercial purposes, or adapted, remixed, transformed or built upon. (https://creativecommons.org/ licenses/by-nc-nd/4.0/)

Georg Thieme Verlag KG, Rüdigerstraße 14, 70469 Stuttgart, Germany 


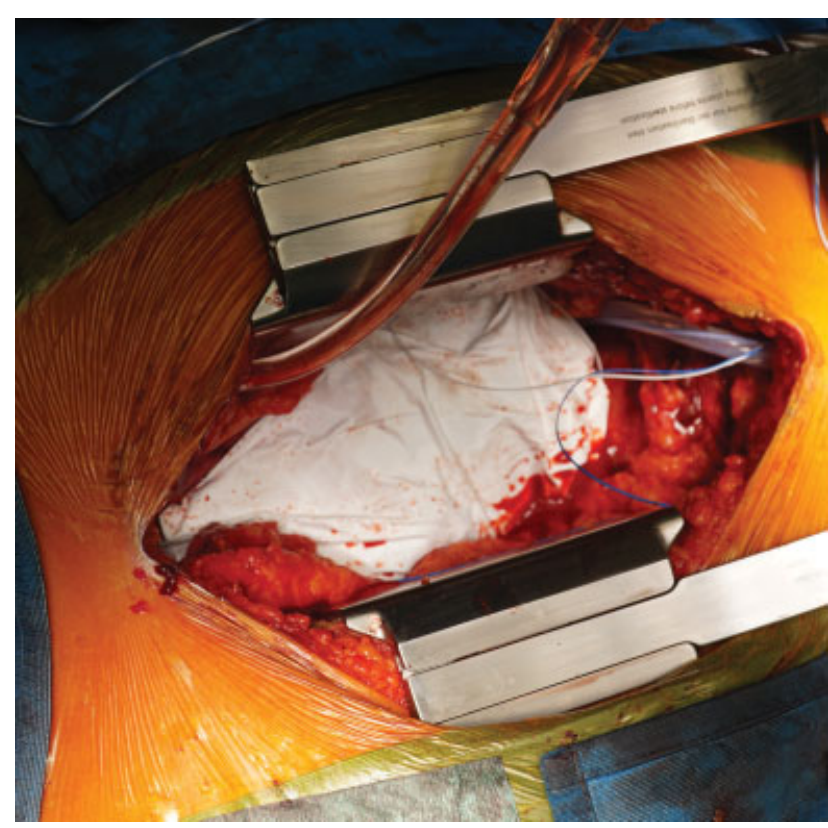

Fig. 1 Intraoperative view depicting the implantation of the neopericardium.

Echocardiography and diagnostic hemodynamic cardiac catheterization also confirmed the diagnosis of constrictive pericarditis. Valve sparing aortic root replacement (David procedure) with leaflet repair, ascending aorta replacement, and pericardiectomy was indicated. Informed consent of the patient was obtained.

After median sternotomy, a thickened $(0.5-1 \mathrm{~cm})$ leatherlike pericardium with significant adhesions was observed. A "from phrenic to phrenic" and diaphragmatic pericardiectomy was performed. After successfully performing the above-mentioned operative steps, an expanded polytetrafluoroethylene (e-PTFE) neo-pericardium (GORE PRECLUDE) was implanted (-Fig. 1). Postoperatively, after an uneventful recovery, the patient was discharged asymptomatic after 7 days. Transthoracic echocardiography at discharge showed an ejection fraction of $62 \%$, no sign of constrictive pericarditis, and a good surgical outcome without any residual aortic insufficiency.

Two years and 2 months after the initial operation the patient was readmitted with progressive dyspnea and marked limitation of ordinary activity (New York Heart Association III). A diagnosis was made: echocardiography and diagnostic hemodynamic cardiac catheterization (re-)confirmed the diagnosis of constriction. After median re-sternotomy the neo-

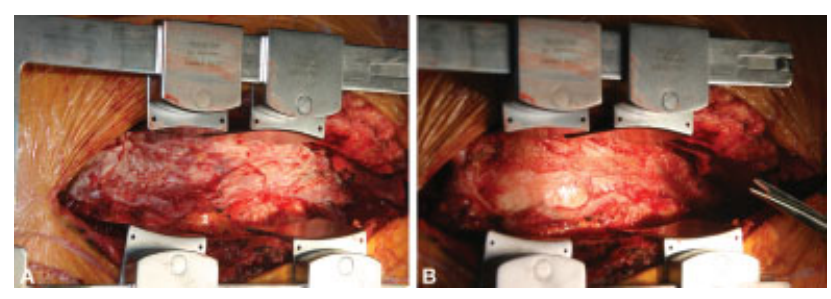

Fig. 2 Intraoperative view depicting the layer of granulation tissue during the reoperation. (A) The ePTFE patch being excised; (B) the layer of granulation tissue under the patch. ePTFE, expanded polytetrafluoroethylene. pericardium was excised, under which a layer of granulation tissue of approximately $5 \mathrm{~mm}$ assembling a foreign body reaction was observed under the whole length of the e-PTFE patch (-Fig. 2). The layer was completely excised and biopsy samples were sent to the pathology laboratory. The result reported a pattern of chronic inflammation and nodular aggregation of lymphocytes, confirming a foreign-body granulomatous reaction. After the surgery the patient recovered uneventfully and was discharged after 6 days. Laboratory data before and after the operations are presented in -Table 1.

\section{Discussion}

Constrictive pericarditis limits the diastolic ventricular filling of the heart with the resulting pathophysiological cascade of reduced cardiac output and congestion. Surgical pericardiectomy can restore the normal physiology, provided that there is no cardiomyopathic component. It has been shown that radical pericardiectomy is superior to conventional in terms of long-term mortality, right ventricular systolic pressure, and tricuspidal regurgitation. ${ }^{5}$

Surgical implantation of a neo-pericardium in patients undergoing cardiac surgery and having a high probability of reoperation is recommended to avoid adverse intraoperative events during the eventual reoperation. Pericardial reconstruction is also indicated after pneumonectomy with pericardiotomy or pericardiectomy as prophylaxis of heart herniation, a condition associated with a very high mortality because of the torsion of the atriocaval junction and great vessels. ${ }^{6}$ Therapeutic reconstruction can also be performed for symptomatic congenital pericardial agenesis.

The pericardium can be reconstructed using biological (heterologous or autologous) or synthetic material, each having their pros and cons. The bovine pericardial patch as heterologous biological material has been demonstrated to be a strong and versatile surgical material but can elicit a hypersensitivity reaction. ${ }^{7}$ On the other hand, autologous material such as pleural or pericardial fat flap is well tolerated and infection-resilient but not strong enough. ${ }^{8}$ Fascia lata flaps have the disadvantage of requiring a secondary incision and operative field. Synthetic meshes have become the material of choice and the Gore-Tex SM emerged as an optimal option for pericardioplasty. ${ }^{3,4}$

In this case report, we present a patient who developed recurrent delayed cardiac constriction after implantation of an e-PTFE SM needing a reoperation for relieving the constrictive component. The pathology report indicated a foreign-body granulomatous reaction. Sakuma and colleagues ${ }^{9}$ demonstrated in an experimental study that e-PTFE sheets can cause extensive inflammatory reaction. Macrophages are the main cell type implicated in the inflammatory reaction against implanted materials ${ }^{10,11}$ and based on the available evidence, the steps of the inflammatory response leading to granulation tissue formation are the following: protein adsorption on the surface of the implant, coagulation cascade initiation, monocyte adhesion, macrophage activation, and foreign-body giant cell formation. ${ }^{10,12}$ New 
Table 1 Laboratory data

\begin{tabular}{|c|c|c|c|c|}
\hline & $\begin{array}{l}\text { Before the } \\
\text { first surgery }\end{array}$ & $\begin{array}{l}\text { After the } \\
\text { first surgery }\end{array}$ & $\begin{array}{l}\text { Before the } \\
\text { second surgery }\end{array}$ & $\begin{array}{l}\text { After the } \\
\text { second surgery }\end{array}$ \\
\hline $\operatorname{CRP}(0,0-0.5 \mathrm{mg} / \mathrm{dL})$ & 0.7 & 11.4 & 0.8 & 6.8 \\
\hline $\begin{array}{l}\text { White cell count } \\
4,600-10,200 / \mu \mathrm{L}\end{array}$ & 9,540 & 11,810 & 9,060 & 16,470 \\
\hline $\begin{array}{l}\text { Neutrophils, \% } \\
51.0-74.0 \%\end{array}$ & & 58.4 & & \\
\hline $\begin{array}{l}\text { Lymphocytes, \% } \\
25.0-45.0 \%\end{array}$ & & 16.1 & & \\
\hline $\begin{array}{l}\text { Monocytes, \% } \\
0-14.0 \%\end{array}$ & & 10.5 & & \\
\hline $\begin{array}{l}\text { Eosinophils, \% } \\
1.0-4.0 \%\end{array}$ & & 13.2 & & \\
\hline $\begin{array}{l}\text { Basophils, \% } \\
0-1.0 \%\end{array}$ & & 0.5 & & \\
\hline Immature granulocytes \% & & 1.3 & & \\
\hline $\begin{array}{l}\text { Thrombocytes } \\
150-40010^{3} / \mu \mathrm{L}\end{array}$ & 265 & 432 & 218 & 125 \\
\hline $\begin{array}{l}\text { Hemoglobin } \\
14-18 \mathrm{~g} / \mathrm{dL}\end{array}$ & 14.5 & 10.4 & 13.5 & 11.8 \\
\hline
\end{tabular}

Abbreviation: CRP, C-reactive protein.

materials may diminish the secretion of cytokines and immune activation but they are currently in in vitro phase. ${ }^{10}$

\section{Conclusion}

We report a case of recurrent delayed cardiac constriction with the confirmed morphological correlate of foreign-body reaction following the implantation of a polytetrafluoroethylene (e-PTFE) neo-pericardium (GORE PRECLUDE Pericardial Membrane) SM. A highly differentiated algorithm and a careful preoperative review of indication is recommended to plan the optimal method of pericardioplasty, taking into account the pros and cons of each available material.

\section{Funding}

No funding was received.

\section{Conflict of Interests}

None.

\section{References}

1 Roselli EE, Pettersson GB, Blackstone EH, et al. Adverse events during reoperative cardiac surgery: frequency, characterization, and rescue. J Thorac Cardiovasc Surg 2008;135(02):316-323, 323. e1-323.e6

2 Gabbay S, Guindy AM, Andrews JF, Amato JJ, Seaver P, Khan MY. New outlook on pericardial substitution after open heart operations. Ann Thorac Surg 1989;48(06):803-812
3 Minale C, Nikol S, Hollweg G, Mittermayer C, Messmer BJ. Clinical experience with expanded polytetrafluoroethylene Gore-Tex surgical membrane for pericardial closure: a study of 110 cases. J Card Surg 1988;3(03):193-201

4 Jacobs JP, Iyer RS, Weston JS, et al. Expanded PTFE membrane to prevent cardiac injury during resternotomy for congenital heart disease. Ann Thorac Surg 1996;62(06):1778-1782

5 Choi MS, Jeong DS, Oh JK, Chang SA, Park SJ, Chung S. Long-term results of radical pericardiectomy for constrictive pericarditis in Korean population. J Cardiothorac Surg 2019;14(01):32

6 Kawamukai K, Antonacci F, Di Saverio S, Boaron M. Acute postoperative cardiac herniation. Interact Cardiovasc Thorac Surg 2011; 12(01):73-74

7 Lazarou G, Powers K, Pena C, Bruck L, Mikhail MS. Inflammatory reaction following bovine pericardium graft augmentation for posterior vaginal wall defect repair. Int Urogynecol J Pelvic Floor Dysfunct 2005;16(03):242-244

8 Veronesi G, Spaggiari L, Solli PG, Pastorino U. Cardiac dislocation after extended pneumonectomy with pericardioplasty. Eur J Cardiothorac Surg 2001;19(01):89-91

9 Sakuma K, Iguchi A, Ikada Y, Tabayashi K. Closure of the pericardium using synthetic bioabsorbable polymers. Ann Thorac Surg 2005;80(05):1835-1840

10 Lamichhane S, Anderson JA, Vierhout T, Remund T, Sun H, Kelly P. Polytetrafluoroethylene topographies determine the adhesion, activation, and foreign body giant cell formation of macrophages. J Biomed Mater Res A 2017;105(09):2441-2450

11 Roch T, Kratz K, Ma N, Lendlein A. Inflammatory responses of primary human dendritic cells towards polydimethylsiloxane and polytetrafluoroethylene. Clin Hemorheol Microcirc 2016;64(04): 899-910

12 Sheikh Z, Brooks PJ, Barzilay O, Fine N, Glogauer M. Macrophages, foreign body giant cells and their response to implantable biomaterials. Materials (Basel) 2015;8(09):5671-5701 